\title{
Sleep Apnea: Traffic and Occupational Accidents - Individual Risks, Socioeconomic and Legal Implications
}

\section{Daniel Rodenstein}

Pneumology Department and Center for Sleep Medicine, Cliniques Universitaires Saint-Luc, Université Catholique de Louvain, Brussels, Belgium

\section{Key Words}

Sleep apnea $\cdot$ Motor vehicle accidents · Sleep medicine • Traffic accidents

\begin{abstract}
Obstructive sleep apnea has been associated with a high risk for motor vehicle accidents, probably the highest of all risks due to medical conditions. Treatment of sleep apnea with nasal continuous positive airway pressure appears to reduce the risk of traffic accidents to the one of the general population. The risk for accidents may also be increased in untreated patients in the home and work environment. The increased risk seems unrelated to the symptom of daytime excessive sleepiness, and in many studies lacks a clear doseresponse relationship with respect to the severity of apneas and hypopneas. The association of sleep apnea, chronic sleep deprivation and consumption of hypnotics or alcohol has not been thoroughly studied, although alcohol has been considered as a confounding variable in some studies. The cost of traffic accidents due to sleep apnea has been estimated to be so high that diagnosing and treating all drivers with sleep apnea in the USA would be cost saving and result in a decrease in society costs related to the disease. Driving licenses are delivered according to national legislations.
\end{abstract}

These are all but uniform, especially concerning sleep apnea. Even within the European Union, where a minimum set of rules is mandatory for all countries, sleep apnea is not included in the minimum. Therefore, drivers are left in a very uncomfortable position, behaving according to the law in one country but being unlawful once the border with the neighbor country is crossed. Physicians are also in a very difficult position if they have to counsel their patients on the best attitude when travelling by car. The situation is even worse for commercial drivers, for whom the legislation is more severe but leaves sleep apnea uncovered in many countries. This is all the more disturbing if one considers that sleep apnea can be suspected, screened and diagnosed with relative ease, and that once diagnosed the adequate treatment allows for safe driving. The inclusion of sleep apnea in the European traffic license regulations would represent a step forward towards safe routes for patients and healthy people alike.

Copyright $\odot 2009$ S. Karger AG, Basel

Previous articles in this series: 1. Riha RL: Genetic aspects of the obstructive sleep apnoea/hypopnoea syndrome - is there a common link with obesity? Respiration 2009;78:5-17. 2. Verbraecken JA, De Backer WA: Upper airway mechanics. Respiration 2009; 78:121-133.

\section{KARGER}

Fax +4161306 1234 E-Mail karger@karger.ch www.karger.com (c) 2009 S. Karger AG, Basel 0025-7931/09/0783-0241\$26.00/0

Accessible online at:

www.karger.com/res
Daniel Rodenstein

Cliniques Saint-Luc

Avenue Hippocrate 10

BE-1200 Brussels (Belgium)

Tel. +32 2764 2886, Fax +32 2764 2831, E-Mail daniel.rodenstein@uclouvain.be 


\section{Introduction}

Irrespective of the presence and intensity of the symptom 'sleepiness', patients suffering from obstructive sleep apnea (OSA) are at increased risk of motor vehicle accidents (MVA) when driving. The body of evidence on this issue is large and independent of cultural, topographic and traffic density backgrounds. Increased risks have been found in countries as dissimilar as Japan, Canada, the USA, Germany, Spain, Switzerland, the UK, France and Australia. Across all studies, the risk of MVA for patients, compared to the general population, is increased by about a factor of 3 .

Work and home accidents have been much less studied, and only scarce data have been published. Though scant, these data point, again, to an increased risk for patients with OSA.

The other concordant information coming from several countries is that the treatment of OSA with continuous positive airway pressure (CPAP) applied during sleep, if adequately used by patients, reduces the increased risk of MVA to the one seen in the general population.

Seen from a distance, the summary of this information leads to a seemingly simple situation: drivers with untreated OSA have about a threefold increased risk for MVA, whereas drivers with CPAP-treated OSA have no increased risk. From a closer viewpoint, however, the picture gets blurred. Many investigators have not found a relation between the severity of the disease and the size of the risk (although a minority of studies showed such an effect). This is quite disturbing. Indeed, one would expect that if it is the consequences of OSA that produce MVA, the more severe the disease, the greater the risk. This dose-response relationship has great practical value, since it may help to grade the risk and identify highest risk groups. In addition, it is a robust argument supporting the causal role of OSA in explaining the increased rate of MVA. Thus, the absence of a dose-response relationship makes the OSA-MVA relation less convincing.

Moreover, MVA risk seems to be unrelated to excessive daytime sleepiness, one of the consequences of OSA that is a logic culprit in accounting for MVA risk. This is also worrying, but less so. Sleepiness is a self-perception that can be influenced by the disease itself, so that sleepy patients may be partially unaware of their degree of sleepiness and fill in questionnaires of sleepiness with answers that deny sleepiness. On the other hand, measuring sleepiness with external tests that do not rely on the patient's own perception has proved difficult to apply on a large scale, and data are simply lacking on any relation between
Table 1. Examples of everyday questions without easy answers

Can I drive if I stop CPAP for a weekend?

Can I drive if I stop CPAP for one night?

For how long should I be on treatment before I can drive safely?

How many hours of CPAP per night will allow me to drive safely?

Can I still safely transport my neighbour's children to school?

My sleep clinic report states that I have an apnea/hypopnea index of 6 (or 10,12, etc.) per hour. They state that I need no treatment with CPAP. Can I safely continue driving?

externally detectable somnolence and MVA risk. It is not clear that sleepiness is the OSA-associated trait that is responsible for MVA increased risk. It could as well be intermittent hypoxia, through unknown mechanisms, that determines a dysfunction of executive functions and cognitive integration.

To make things more complicated, it has to be recalled that MVA are generally the final consequence of multiple causes. From a simple decrease in attention, to bad weather conditions modifying the braking distances, to bad road conditions, to the motor vehicle maintenance level, to the tire pressure and state, to blood alcohol levels, to previous night sleep duration and quality, to mood, medications and drugs consumption, and to circadian aspects (that is, time of day), all these aspects will ultimately, alone or in combination, explain why an MVA has taken place.

When a diagnosis of OSA is made in a given patient, it is reasonable to assume that the patient will be informed that he is at increased risk for MVA, and that he should react in an appropriate way to this new information. The problem arises when the patient starts asking questions, which will be very specific and very important for the patient, and for which physicians will not have precise, satisfactory and clear answers. Examples of such questions are given in table 1. Although it should be acknowledged that drivers spend most of their time blocked in traffic jams, driving a private car enables most of us to live far from where we work, from our children's school, from our families and friends or from shops and groceries. Being deprived from driving a car because one could have an MVA (although one has in fact never had one) may be devastating. Having an actual MVA may be tragic. Physicians will not escape easily from the need to face these questions and try to honestly answer them despite 
uncertainties and lack of information. The matter is even more dramatic for someone making his living out of driving. It has been calculated that more than $10 \%$ of the workforce in Western societies are drivers, whether of person transport vehicles, from taxis to buses, trains or planes or of small and large goods transport vehicles.

From the society point of view, diseases imply costs, both because the patient may decrease his earning capacities and because health care for the patient will need expenses. In the case of MVA due to OSA, society will face costs that are beyond the health care budget. Usually, these costs will not be considered when assessing the economic impact of a disease. In OSA, these costs should be taken into account to understand the global economic implications of the disease and its treatment.

There are legal questions linked to the MVA risk in OSA. One of the most important is the legal framework for driving license regulations. In many European countries (as well as for instance in many Australian regions) OSA is specifically considered in the national driving license regulations. In others it is not. European rules try to harmonize national rules and set minimal standards to which all EU countries must comply. Unfortunately, OSA is not mentioned in the medical sector of the European Driving License Regulations (Annex III of the European Directive 91/439/EEC). Physicians are usually not at ease with legal questions. Nevertheless, they may be the only ones that can advise a patient with OSA driving abroad about the fact that driving regulations may differ, and greatly so, from one country to another, at least until the EU decides to harmonize rules concerning OSA and driving. It is worth mentioning that OSA is not the only medical condition having a deleterious influence on driving ability. But it should also be mentioned that of all medical conditions leading to an increase in MVA risks, OSA carries by far the greater risk increase, which makes it all the more necessary to homogenize driving license regulations in a continent where crossing borders has become commonplace for millions of drivers.

The following pages will review in more detail some of the above mentioned aspects of OSA, that although not related to health, are worth knowing for physicians interested in sleep apnea.

\section{OSA and MVA: The Evidence}

The first reports of an increased number of MVA in patients with sleep apnea were published in the late 1980s $[1,2]$. These reports brought MVA to the medical realm, and prompted the inclusion of questions on sleepiness while driving and of MVA into the usual questions to be considered in patients with OSA. Many reports have been published since then, using different methodologies, from epidemiologic studies to cohort studies, case-control studies and follow-up studies. Several investigators relied on patient's responses to these questionnaires (subjective data), whereas many others turned to official databases of MVA (in general more serious accidents involving personal injuries or significant financial consequences). Several papers have reported on the effects of treatment (usually with CPAP) on MVA, comparing, in a cohort of patients, the rate of MVA for a given time before and after the institution of therapy. Patients were frequently compared with a control sample, either limited in number and matched to the patient group on several aspects or including all the population in a given geographical area (an island, a state). In most studies, many factors that could influence the comparisons were accounted for in the calculations. These include, for instance, distance driven per year, visual troubles, medications and alcohol consumption, body mass index, smoking, work schedule, and comorbidities. Most studies have probed the possible relationships between the severity of the disease, assessed either through the apnea/hypopnea index (AHI) or the desaturation index, or the severity of the disease-related sleepiness, usually assessed with the Epworth Sleepiness Scale, or some index of sleep fragmentation such as the Movement Arousal Index on the one hand, and the rate of MVA on the other hand. Table 2 shows summary data of many such studies.

Whatever the population sample considered, whatever the methodology of the study, whatever the follow-up length, whether studies rely on self-reported MVA rate or on official databases, the results are concordant: there is an increased risk for MVA in patients with OSA, either for MVA in general or for serious MVA only, and this excess is cancelled when patients start and remain on treatment with CPAP. The average increase in risk across all studies is in the range of 3 -fold with respect to the general population.

As previously stated, only about half the published studies have found some relationship between the severity of OSA and the risk for MVA. When this is the case, the relationship is generally not linear, but rather there is a kind of threshold above which the risk increases. For instance, in the study by Horstmann et al. [10], patients with MVA had an AHI $>34$. In the study by George and Smiley [14], the threshold was an AHI of 40. In other studies, the limit is just an $\mathrm{AHI}$ of more than 5 events per 
Table 2. Main studies on obstructive sleep apnea and MVA

\begin{tabular}{|c|c|c|c|c|c|c|}
\hline Reference & Type of study & Samples studied & $\begin{array}{l}\text { Matching } \\
\text { aspects }\end{array}$ & Main outcome & $\begin{array}{l}\text { Confounding } \\
\text { variables analyzed }\end{array}$ & Main result \\
\hline $\begin{array}{l}\text { Casel } \\
\text { et al. [3] }\end{array}$ & $\begin{array}{l}\text { cohort follow-up } \\
1 \text { year after CPAP start }\end{array}$ & $\begin{array}{l}\text { CPAP-treated OSA } \\
(\mathrm{n}=59)\end{array}$ & NA & accident rate & $\mathrm{km}$ driven & $\begin{array}{l}\text { reduction of MVA on } \\
\text { treatment }\end{array}$ \\
\hline $\begin{array}{l}\text { Engleman } \\
\text { et al. [4] }\end{array}$ & $\begin{array}{l}\text { cohort follow- up } \\
2 \text { years after CPAP start }\end{array}$ & $\begin{array}{l}\text { CPAP-treated OSA } \\
(\mathrm{n}=147)\end{array}$ & NA & near miss incidents & miles driven & $\begin{array}{l}\text { reduction after CPAP } \\
\text { institution }\end{array}$ \\
\hline $\begin{array}{l}\text { Krieger } \\
\text { et al. [5] }\end{array}$ & $\begin{array}{l}\text { cohort follow-up } 1 \text { year } \\
\text { before and } 1 \text { after } \\
\text { CPAP start }\end{array}$ & CPAP-treated OSA & NA & $\begin{array}{l}\text { MVA vs. the general } \\
\text { French population } \\
\text { data }\end{array}$ & NA & $\begin{array}{l}\text { excess risk (21-fold) } \\
\text { decreased after CPAP } \\
\text { institution (to }>6 \text {-fold) }\end{array}$ \\
\hline $\begin{array}{l}\text { Young } \\
\text { et al. [6] }\end{array}$ & epidemiologic & $\begin{array}{l}\text { employed adults } \\
\mathrm{n}=913\end{array}$ & NA & $\begin{array}{l}\text { accident rate OSA } \\
\text { vs. others }\end{array}$ & $\begin{array}{l}\text { gender, alcohol, } \\
\text { education, } \mathrm{km} \text { driven, } \\
\text { age }\end{array}$ & $>3$-fold risk \\
\hline $\begin{array}{l}\text { Barbé } \\
\text { et al. [7] }\end{array}$ & case-control & $\begin{array}{l}\text { OSA/control } \\
n=60+60\end{array}$ & sex, age & MVA rate & $\begin{array}{l}\text { age, alcohol, km } \\
\text { driven }\end{array}$ & $\begin{array}{l}>2 \text {-fold for single and } \\
>5 \text {-fold for multiple } \\
\text { accidents risk }\end{array}$ \\
\hline $\begin{array}{l}\text { Teran- } \\
\text { Santos } \\
\text { et al. [8] }\end{array}$ & case-control & $\begin{array}{l}\text { road accident } \\
\text { drivers/controls } \\
\mathrm{n}=102+152\end{array}$ & sex, age & OSA accident rate & $\begin{array}{l}\text { alcohol, visual troubles, } \\
\text { BMI, driving } \\
\text { experience and km } \\
\text { driven, age, drugs, } \\
\text { HTA }\end{array}$ & $>7$-fold risk \\
\hline $\begin{array}{l}\text { Findley } \\
\text { et al. [9] }\end{array}$ & $\begin{array}{l}\text { cohort follow-up } \\
2 \text { years before and } \\
2 \text { after CPAP start }\end{array}$ & $\begin{array}{l}\text { OSA on CPAP vs. } \\
\text { Colorado State } \\
\text { drivers }\end{array}$ & NA & $\begin{array}{l}\text { MVA rate vs. } \\
\text { Colorado drivers, } \\
\text { evolution on CPAP } \\
\text { or untreated }\end{array}$ & NA & $\begin{array}{l}>7 \text { MVA risk in OSA } \\
\text { patients; untreated } \\
\text { patients conserved } \\
\text { increased risk, that was } \\
\text { cancelled in treated } \\
\text { patients }\end{array}$ \\
\hline $\begin{array}{l}\text { Horstmann } \\
\text { et al. [10] }\end{array}$ & case-control & $\begin{array}{l}\text { OSA/control } \\
\mathrm{n}=156+160\end{array}$ & sex, age & $\begin{array}{l}\text { accident rate/million } \\
\text { driven } \mathrm{km}\end{array}$ & $\begin{array}{l}\text { BMI, alcohol, sleeping } \\
\text { pills }\end{array}$ & $>8$-fold risk \\
\hline $\begin{array}{l}\text { Masa } \\
\text { et al. [11] }\end{array}$ & case-control & $\begin{array}{l}\text { sleepy drivers/ } \\
\text { control } \\
n=107+109\end{array}$ & sex, age & accident rate & $\begin{array}{l}\text { alcohol, BMI, HTA, } \\
\text { hours driven, years } \\
\text { driving, drugs }\end{array}$ & $\begin{array}{l}>3 \text {-fold risk for AHI } \\
>10,>5 \text {-fold risk for } \\
\text { AHI }>15\end{array}$ \\
\hline $\begin{array}{l}\text { Yamamoto } \\
\text { et al. [12] }\end{array}$ & $\begin{array}{l}\text { cohort follow-up } \\
2 \text { years before and } \\
2 \text { after CPAP start }\end{array}$ & $\begin{array}{l}\text { OSA on CPAP } \\
\mathrm{n}=47\end{array}$ & NA & $\begin{array}{l}\text { \%age with MVA and } \\
\text { near miss }\end{array}$ & NA & $\begin{array}{l}33 \% \text { of patients had an } \\
\text { MVA (and } 88 \% \text { had a } \\
\text { near miss) before CPAP; } \\
\text { after CPAP the } \\
\text { proportion fell to } 0 \text { and } \\
9 \% \text {, respectively }\end{array}$ \\
\hline $\begin{array}{l}\text { Mulgrew } \\
\text { et al. [13] }\end{array}$ & case-control & $\begin{array}{l}\text { OSA/controls } \\
\mathrm{n}=783\end{array}$ & $\begin{array}{l}\text { sex, age, } \\
\text { driving } \\
\text { license type, } \\
\text { residence }\end{array}$ & $\begin{array}{l}\text { MVA, MVA with } \\
\text { personal injury }\end{array}$ & $\begin{array}{l}\text { BMI, sleepiness, sex, } \\
\text { age, km driven, } \\
\text { alcohol, sedatives, } \\
\text { caffeine }\end{array}$ & $\begin{array}{l}>3 \text {-fold risk for severe } \\
\text { MVA with personal } \\
\text { injury, not for MVA in } \\
\text { general }\end{array}$ \\
\hline
\end{tabular}

$\mathrm{BMI}=$ Body mass index HTA = arterial hypertension; NA = not applicable.

hour, just above the figure defining the limit of normality in sleep studies. Concerning sleepiness, most studies show a lack of relationship between MVA and the usual way of assessing sleepiness, that is, the Epworth Sleepiness Scale.

It is interesting at this point to remind the reader that OSA is not the only medical condition leading to an increase in MVA risk. Many diseases are known to result in
MVA, from visual refraction troubles, to cardiac arrhythmias, neurological diseases like epilepsy, hearing troubles, rheumatic diseases and the like. A recent meta-analysis compared the risks for MVA in all medical conditions reported in the literature [15]. The summary of this meta-analysis is that most medical conditions confer a risk increased between 1.2- and 2-fold with respect to a healthy population (meaning that the disease increases 
the MVA rate by $20-100 \%)$. OSA had the highest increased risk, with a relative risk of 3.71, which is second only to age and gender as a general risk factor for MVA.

For home and work accidents, the data are very poor. Only Krieger et al. [5] have systematically assessed these questions in their cohort of 893 patients followed up for 12 months after the start of CPAP treatment. Domestic accidents decreased from 25 before therapy to 13 after therapy, whereas near miss accidents fell from 65 to 8 . Work accidents decreased from 12 to 7 , and near miss work accidents from 63 to 2. Sixty patients declared an accident before treatment, whereas the figure fell to 36 after CPAP treatment. For near miss accidents, the figures were 151 and 32, respectively.

Barbé et al. [16] have recently performed a case-control study showing that 80 patients with sleep apnea had a 2.6 times higher risk of traffic accidents with respect to the control group. When studied 2 years after the start of treatment, the rate of accidents had halved in patients, but also in the control group. This points to awareness as being an important stimulus for the reduction in traffic accidents, at least in the control group, that knew they were being followed up for motor vehicle collisions.

\section{MVA, Sleepiness and Sedative Drugs}

The literature on sleepiness and MVA is large, and will not be reviewed in any detail here. However, there are some points that are relevant when considering patients with OSA. Sleepiness is thought to be involved in 10-20\% of all MVA [17]. Sleepiness is physiologically related to the circadian rhythm in man. Thus, a report by Connor et al. [18] showed that among 571 car drivers involved in serious MVA (with personal injuries or deaths), compared to 588 control drivers, the risk of MVA was causally related to sleeping less than $5 \mathrm{~h}$ in the previous $24 \mathrm{~h}$, to driving at an inappropriate circadian time, that is, between 2 and $5 \mathrm{a}$. $\mathrm{m}$., and to being subjectively sleepy at the time of the MVA [18]. Similarly, Garbarino et al. [19] among others have clearly shown an excess rate of MVA during the circadian peaks in sleepiness, despite the low traffic density at these times. These are important messages to be conveyed to patients with OSA when discussing ways to decrease the risk for MVA, and to avoid other factors possibly increasing this risk beyond OSA itself. The well-known effects of alcohol consumption, even in seemingly low quantities, are of course worth mentioning.

Sedating drugs are among the most sold medicines in the world. This generic word is used here to describe drugs with sedative effects, sleep-prone effects, antipsychotic drugs and antidepressants. To these categories, one should add narcotic pain killers and antihistamine drugs. All these medicines decrease fitness to drive, not only shortly after their intake but many hours later, depending on the compound $[20,21]$.

These facts should be brought to the attention of patients with OSA at the time of diagnosis and during CPAP treatment implementation.

\section{MVA, Sleep Apnea and Costs}

Some investigators have tried to estimate the costs attributable to MVA related to OSA. Starting from published values of OSA prevalence, an odds ratio for MVA in patients with OSA calculated as 2.52 and the percentage of drivers older than 25 years (it is assumed that there are few patients with sleep apnea below this age), they computed the percentage of MVA and of related fatalities that could be attributed to patients with OSA, above the one expected in the population in general [22]. They then calculated comprehensive costs related to MVA, as obtained from USA official sources for the year 2000. These costs included not only medical expenses but also wages and productivity losses, administrative expenses, vehicle damages and employer costs for damages to working drivers. They also added lost financial values due to fatalities, and lost financial values due to a low quality of life after an MVA.

On a separate calculation, the cost of diagnosing sleep apnea and instituting CPAP treatment for all American drivers was computed. The authors assumed that only 1 in 5 screened drivers actually would have OSA, would be treated with CPAP and therefore would be protected from incurring the costs related to MVA in OSA. Very conservatively, Sassani et al. [22] also assumed the effectiveness of CPAP to be only $70 \%$.

The summary of the results is that OSA-related MVA represent a cost of about USD 16 billion per year. Treating all drivers with CPAP would reduce the cost by about USD 11 billion per year. The cost of screening, diagnosing and treating all drivers was calculated at USD 3.2 billion, leading to annual savings of USD 7.9 billion. These sums come from an estimated 810,000 collisions per year and 1,400 fatalities attributable to OSA-related MVA. Some 567,000 collisions and 980 fatalities could be avoided with CPAP treatment every year.

Sensitivity analysis with a number of different variables did not change the results in any significant way. 
This report differs from many others on similar subjects [23] because it includes all costs resulting from MVA, not only related to the medical realm but also to the labour, insurance and administration markets, and makes place for financial equivalents for lost quality of life and for lost lives.

\section{Sleep Apnea and Driving License: The European Landscape}

Diseases may impair the ability of the patient to execute delicate motor and cognitive tasks. It has long been recognized that operating machines and motor engines may be impaired not only by disease but also by medicines. Thus, every country has established a list of medical conditions that restrict or forbid altogether access to the driving license. This is an evolving field and different countries have issued different lists. Moreover, the list may differ for private drivers and professional drivers, the latter being in general more extensive and precise.

Having established the list, it became necessary to designate the persons able to declare whether the candidate driver did or did not have the listed diseases, whether the severity of the disease justified an exception to the usual attitude, and whether the decision should apply for a limited time or be considered as definitive.

Depending on local history, politics and habits, the geographical limits of the driving license issuing board can go from a County (in Switzerland for instance), to a State (as in the USA or Australia) to a whole country (as in Belgium).

The European Union has long promoted the free circulation of people and goods within the 6 , then 10 and nowadays 27 countries union. At least partly, this policy depends on harmonization of national transport legislations. Driving License Regulations have been the object of a European text in 1991, the Council Directive on Driving License Regulations. This text comprises an Annex III, listing the diseases and impairments limiting access to the driving license [24]. This is a common minimum set of conditions that all member countries must comply with. However, individual countries can add other conditions with due justification. Beyond a very limited common set of rules, individual countries remain free to decide on the procedures, issuing boards, medical examination rules and so on.

Concerning OSA, neither the disease nor excessive daytime sleepiness is mentioned in the Annex III to the 1991 directive. There is a general stance on the driver having to always be able to control the vehicle, but with no specific reference to OSA as such.

A recent report has detailed the state of the legislation in 25 European countries [25]. Ten countries specifically mention sleep apnea in their own Annex III (Belgium, Finland, France, Germany, Hungary, The Netherlands, Poland, Spain, Sweden and the UK). In some countries it is the physician's duty to inform the authorities, whereas in some others the physician is forbidden from doing so (Hippocratic oath). In most countries, a patient with OSA cannot drive at all or may drive under restrictive conditions (for instance not driving at night, not driving on highways) as long as he is not treated, whereas he can drive without restrictions if he is treated (but nothing is said on treatment compliance, duration and so on). To this very chaotic scene, it has to be added that the duration of the driving license can vary from one country to the other from lifetime (the driving license is never renewed in Belgium for instance) to 5 or 10 years depending on the age of the applicant. In the near future, the driving license will uniformly be limited in the whole European Union. Directive 2006/126/EC will be enforced in 2013 stating that the driving license has a validity of 10 years for private drivers (although countries may extend this to 15 years) and of 5 years for professional drivers. Unfortunately, the new Annex III is as silent as far as OSA and excessive daytime sleepiness are concerned as was the directive issued in 1991 [26].

This legislative disharmony may put drivers in difficult legal conditions. An Italian driver with untreated OSA is entitled to drive without restrictions in Italy. If he has an MVA in Belgium, even if he is not at fault, he is infringing the law.

There is some hope that OSA will be considered for inclusion in Annex III in the next years (it was already briefly introduced to the Road Safety High Level Group of the European Union in 2007), although it may as well remain ignored [27].

\section{Sleep Apnea, MVA and the Law}

In 2003, Desai et al. [28] published a paper on 7 MVA resulting in fatalities, where the driver was later found to suffer from OSA, idiopathic sleepiness, upper airway resistance syndrome, periodic legs movement disorder or sleep deprivation, alone or in combination. These 7 drivers were brought to court, and an expert medical opinion was requested from the authors. In 5 cases, objective tests of sleepiness showed severe abnormal sleepiness. The fact 
remains rare enough, and this author is not aware of such demands coming from lawyers or courts elsewhere. Things may change in the future, and sleep specialist may find themselves in the midst of prosecutors, defendants and victims.

\section{Screening and Diagnosing Sleep Apnea in Professional Drivers}

The facts concerning OSA and MVA have for the main part been well known since the last decade of the last century. The excess risk for MVA in drivers with OSA has worried many sleep specialists for a long time. In 2006, a Joint Task Force from the American College of Chest Physicians, the American College of Occupational and Environmental Medicine and the National Sleep Foundation published a document on sleep apnea and commercial motor vehicle operators [29]. They restricted their recommendations to commercial drivers and proposed a short screening procedure. In a driver with snoring, excessive daytime sleepiness and/or witnessed apneas, 2 of the following 3 criteria - a body mass index greater than 35, a neck circumference greater than $43.2 \mathrm{~cm}$ in men or $40.6 \mathrm{~cm}$ in women or arterial hypertension - or an Epworth Sleepiness Scale greater than 10, a suspicion of OSA is present and justifies a diagnostic procedure. In the meanwhile, the driver can continue driving.

If the driver has observed unexplained sleepiness (he is sleeping in the waiting room for instance), has had an MVA possibly related to being asleep, has an Epworth Sleepiness Scale greater than 16 or has untreated sleep apnea, driving should not be allowed until the situation has changed.

Very recently, a study appears to validate these recommendations [30]. Out of 1,400 drivers with a commercial license, $13 \%$ screened positive with the Joint Task Force Screening recommendations (none would have been suspected with the usual Commercial Driver Medical Examination Form). Seventy percent of those screened positive underwent polysomnography and 95\% showed OSA. Of course, many other commercial drivers could have gone undetected by the Task Force Screening proposal (for instance the lean patients with severe OSA with little subjective daytime sleepiness). But at least this method might increase the number of undiagnosed drivers with OSA that can be prioritized for a fast track diagnostic procedure.

\section{Conclusion}

It appears that nobody can ignore any more that patients with OSA are at increased risk for MVA and that treatment with CPAP protects from this increased risk. The economic consequences of this increased risk for society are enormous, and the protective effect of CPAP treatment is such that screening, diagnosing and treating all drivers with undiagnosed OSA will result in net savings rather than in increased costs. The combined effects of OSA, sleep deprivation and sedative medications should be much more largely publicized to the general public. Within Europe, the harmonization of national legislations on driving license regulations and the inclusion of OSA as a recognized medical risk for driving in Annex III of the new European Directive should be a priority. Without these moves, physicians in general and sleep specialists in particular will find themselves in a very uncomfortable posture in the face of the law. And patients with OSA, innocent bystanders and healthy drivers will continue to be exposed to a preventable risk.

\section{References}

1 George CF, Nickerson PW, Hanly PJ, Millar TW, Kryger MH: Sleep apnoea patients have more automobile accidents. Lancet 1987; ii:447.

-2 Findley LJ, Unverzagt ME, Suratt PM: Automobile accidents involving patients with obstructive sleep apnea. Am Rev Respir Dis 1988; $138: 337-340$

-3 Casel W, Ploch T, Becker D, Dugnus D, Peter $\mathrm{JH}$, von Wichert P: Risk of traffic accidents in patients with sleep-disordered breathing: reduction with nasal CPAP. Eur Respir J 1996;9:2606-2611.

\footnotetext{
4 Engleman EM, Asgari-Jirhandeh N, McLeof AL, Ramsay CF, Deary IJ, Douglas NJ: Selfreported use of CPAP and benefits of CPAP therapy. Chest 1996;109:470-476.

$\checkmark 5$ Krieger J, Meslier N, Lebrun T, Levy P, Phillip-Joet F, Sailly JC, Racineux JL: Accidents in obstructive sleep apnea patients treated with nasal continuous positive airway pressure. Chest 1997;112:1561-1566.

6 6 Young T, Blustein J, Finn L, Palta M: Sleepdisordered breathing and motor vehicle accidents in a population-based sample of employed adults. Sleep 1997;20:608-613.
}

\footnotetext{
7 Barbé F, Pericas J, Muñoz A, Findley L, Anto JM, Agusti AGN: Automobile accidents in patients with sleep apnea syndrome. Am J Respir Crit Care Med 1998;158:18-22.

-8 Teran-Santos J, Jimenez-Gomez A, CorderoGuevara J: The association between slep apnea and the risk of traffic accidents. N Engl J Med 1999;340:847-851.

-9 Findley L, Smith C, Hooper J, Dineen M, Suratt PM: Treatment with nasal CPAP decreases automobile accidents in patients with sleep apnea. Am J Respir Crit Care Med 2000;161:857-859.
} 
10 Horstmann S, Hess CW, Bassetti C, Gugger M, Mathis J: Sleepiness-related accidents in sleep apnea patients. Sleep 2000;23:383389.

11 Masa JF, Rubio M, Findley LJ: Habitually sleepy drivers have a high frequency of automobile crashes associated with respiratory disorders during sleep. Am J Respir Crit Care Med 2000;1562:1407-1412.

- 12 Yamamoto H, Akashiba T, Kosaka N, Ito D Horie T: Long-term effects of nasal continuous positive airway pressure on daytime sleepiness, mood and traffic accidents in patients with obstructive sleep apnoea. Respir Med 2000;94:87-90.

-13 Mulgrew AT, Nasvadi G, Butt A, Cheema R, Fox N, Fleetham JA, Ryan CF, Cooper P, Ayas NT: Risk and severity of motor vehicle crashes in patients with obstructive sleep apnoea/ hypopnoea. Thorax 2008;63:536-541.

14 George CFP, Smiley A: Sleep apnea and automobile crashes. Sleep 1999;22:790-795.

15 Vaa T: Impairments, Diseases, Age and Their Relative Risks of Accident Involvement: Results from a Meta-Analysis. Oslo, Institute of Transport Economics, 2003.

-16 Barbé F, Sunyer J, de la Peña A, Pericas J, Mayoralas LR, Antó JM, Agustí AG: Effect of continuous positive airway pressure on the risk of road accidents in sleep apnea patients. Respiration 2007;74:44-49.

$\checkmark 17$ Horne JA, Reyner LA: Sleep related vehicle accidents. BMJ 1995;310:565-567.
18 Connor J, Norton R, Ameratunga S, Robinson E, Civil I, Dunn R, Bailey J, Jackson R Driver sleepiness and risk of serious injury to car occupants: population based case control study. BMJ 2002;324:1125-1130.

19 Garbarino S, Nobili L, Beelke M, De Carli F Ferrillo F: The contributing role of sleepiness in highway vehicle accidents. Sleep 2001;24: 203-206

20 Verster JC, Veldhuijzen DS, Volkerts ER: Residual effects of sleep medication on driving ability. Sleep Med Rev 2004;8:309-325.

21 Gustavsen I, Bramnes JG, Kurtveit S, Engeland A, Neutel I, Morland J: Road traffic accident risk related to the prescription of the hypnotics Zopiclone, Zolpiden, Flunitrazepam and Nitrazepam. Sleep Med 2008;9: 818-822.

22 Sassani A, Findley LJ, Kryger M, Goldlust E, George C, Davidson TM: Reducing motorvehicle collisions, cost, and fatalities by treatein obstructive sleep apnea syndrome. Sleep 2004;27:453-458.

23 Gurubhagavatula I, Nkwuo JE, Maislin G, Pack AI: Estimated cost of crashes in commercial drivers supports screening and treatment of obstructive sleep apnea. Accident Anal Prev 2008;40:104-115.

24 http://ec.europa.eu/transport/road_safety/ behavior/driving_licence_en.htm (accessed February 22, 2009).
25 Alonderis A, Barbe F, Bonsignore M, Calverley P, De Backer W, Diefenbach K, Donic V, Fanfulla F, Fietze I, Franklin K, Grote L, Hedner J, Jennum P, Krieger J, Levy P, McNicholas W, Montserrat J, Parati F, Pascu M, Penzel T, Riha R, Rodenstein D, Sanna A, Schulz R, Sforza E, Sliwinski P, Tomori Z, Tonnesen P, Varoneckas G, Zielinski J, Kostelidou K; Cost Action B-26: Medico-legal implications of sleep apnea syndrome: driving license regulations in Europe. Sleep Med 2008;9:362-375.

26 http://eur-lex.europa.eu/LexUriServ/LexUriServ.do?uri=OJ:L:2006:403:0018:0060: EN:PDF (accessed February 22, 2009).

27 Rodenstein D: Driving in Europe: in need of a common policy for drivers with obstructive sleep apnoea syndrome. J Sleep Res 2008; 17:281-284

28 Desai AV, Ellis E, Wheatley JR, Grunstein RR: Fatal distraction: a case series of fatal fall-asleep road accidents and their medicolegal outcomes. Med J Aust 2003;178:396399.

29 Hartenbaum N, Collop N, Rosen IM, Phillips B, George CFP, Rowley JA, Freedman N, Weaver TE, Gurubhagavatula I, Strohl K, Leaman HM, Moffit GL, Rosekind MR: Sleep apnea and commercial motor vehicle operators. J Occup Environ Med 2006;48: S1-S3.

30 Talmage JB, Hudson TB, Hegmann KT, Thiese MS: Consensus criteria for screening commercial drivers for obstructive sleep apnea: evidence of efficacy. J Occup Environ Med 2008;50:324-329. 